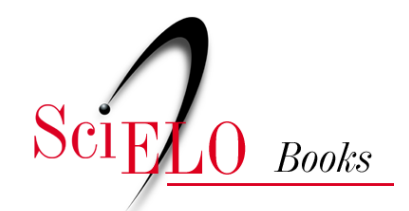

\title{
Em busca de cidades mais justas por meio da tributação imobiliária um olhar sobre as cidades fluminenses
}

\author{
Angela M. S. Penalva Santos
}

\section{SciELO Books / SciELO Livros / SciELO Libros}

SANTOS, A.M.S.P. Em busca de cidades mais justas por meio da tributação imobiliária: um olhar sobre as cidades fluminenses. In: MARAFON, G.J., and RIBEIRO, M.A. orgs. Revisitando o território fluminense, VI [online]. Rio de Janeiro: EDUERJ, 2017, pp. 25-42. ISBN: 978-85-7511457-5. https://doi.org/10.7476/9788575114575.0003.

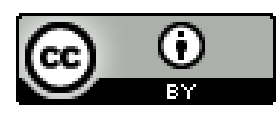

All the contents of this work, except where otherwise noted, is licensed under a Creative Commons Attribution 4.0 International license.

Todo o conteúdo deste trabalho, exceto quando houver ressalva, é publicado sob a licença Creative Commons Atribição $\underline{4.0}$.

Todo el contenido de esta obra, excepto donde se indique lo contrario, está bajo licencia de la licencia $\underline{\text { Creative Commons }}$ Reconocimento 4.0. 


\section{Em busca de cidades mais justas por meio da tributação imobiliária: um olhar sobre as cidades fluminenses ${ }^{1}$}

Angela M. S. Penalva Santos ${ }^{2}$

\section{Introdução}

0 Brasil experimentou grande avanço normativo para ordenar o crescimento urbano desde a entrada em vigor da Constituição de 1988: o município foi institucionalmente fortalecido ao ser considerado "ente federativo" e responsável pela execução de políticas sociais descentralizadas. É também o ente responsável pela política urbana, tendo sido criados vários novos instrumentos de controle do uso do solo urbano, todos regulados pelo Estatuto da Cidade em 2001.

Tal avanço normativo não se manifestou na melhora do ordenamento urbanístico nas grandes cidades. Ao contrário, a intensificação da urbanização da população brasileira seguiu espacialmente polarizada, o que tornou ainda mais desafiadora a gestão dessas cidades. Além do já tradicional problema de inadequação de infraestrutura urbana, a insegurança pública, combinada com a falta de mobilidade urbana, tornou mais difícil a vida nessas cidades, ainda que sigam oferecendo as maiores e melhores oportunidades de emprego, o que alimenta os fluxos migratórios em sua direção (Santos, 2012 e 2014a).

O crescimento da população nas grandes cidades se expressa pela extensão da malha urbana, inclusive para além das fronteiras municipais, o que implica a necessidade de que os municípios expandam suas redes de infraestrutura urbana. Ressalta-se que, à medida que aumenta a responsabilidade financeira dos municípios, a terra urbana se valoriza nos terrenos mais bem localizados. Nessas

1 Este artigo sintetiza parte das conclusões do Grupo de Pesquisa sobre Tributação Imobiliária que coordenei no Programa de Pós-Graduação em Direito, na linha Direito da Cidade. Participaram do grupo os pós-graduandos Pedro Vasques, Natália Sales, Diego Ximenes, Álvaro Carlos Barbosa e Carmem Silvia Mattos.

2 Professora associada da Faculdade de Ciências Econômicas da Universidade do Estado do Rio de Janeiro. Pós-doutora em Planejamento Urbano. 
condições, as prefeituras alimentam um processo de valorização fundiária que desempenha o papel de redistribuir regressivamente a renda real da população. ${ }^{3}$

O aumento do preço da terra urbana é um fenômeno que não se restringe às nossas cidades, parecendo ser generalizado, como sugerem as análises de Thomas Piketty a respeito das mudanças na estrutura da riqueza nos últimos três séculos. Com base em dados sobre França e Reino Unido, esse autor mostra que, no início do século XVIII, a terra rural representava mais da metade da forma como a riqueza se manifestava. A Revolução Industrial levou à diversificação dessa riqueza no século XIX e, desde a segunda metade do século XX, é a riqueza em forma de terra urbana (moradias) que mais tem crescido, correspondendo a cerca da metade do patrimônio acumulado em 2010 (Piketty, 2014, pp. 118-9).

O processo de urbanização com polarização espacial nas grandes cidades, associado ao aumento do preço da terra urbana, produz efeitos socioespaciais negativos. Segregação urbana, insegurança pública e aumento dos movimentos pendulares são alguns desses efeitos que pesam, de forma significativa, sobre as condições de vida da população urbana mais vulnerável. E são fatores que desafiam os governos locais a buscarem melhorar a gestão urbana.

Este artigo visa a defender o avanço na tributação imobiliária como uma forma de: i) aumentar as receitas próprias dos municípios, elevando suas receitas orçamentárias, de modo a permitir o financiamento da expansão da infraestrutura urbana; e, principalmente, ii) ser utilizado como instrumento de política urbana comprometida com cidades mais sustentáveis e inclusivas.

Divide-se na presente introdução, seguida por uma seção sobre a normatividade do IPTU para fins de política urbana, em que se apresenta uma síntese dos estudos sobre o emprego desse tributo na América Latina. Na terceira seção, apresentam-se dados que caracterizam as finanças públicas municipais, destacando o papel da tributação imobiliária nos municípios brasileiros, com foco para aqueles que têm população superior a duzentos mil habitantes, em particular os localizados no estado do Rio de Janeiro. Por fim, a quarta seção é destinada às considerações conclusivas, apontando para a enorme distância entre a norma e a efetividade no uso do IPTU como instrumento de política urbana ou arrecadatória.

\section{A tributação imobiliária no Brasil}

A Constituição Federal brasileira proclama o caráter social que deve ser conferido à propriedade, regrando, repetidas vezes, em vários dispositivos, sua função social. ${ }^{4}$ Ademais, influenciado pelo

3 Renda real é um conceito que não se restringe à renda monetária, incluindo o conjunto de acesso às condições de vida, que podem ser ampliados por meio da disponibilidade de infraestrutura urbana provida pelo poder público.

${ }^{4}$ Art. 5, XXII: é garantido o direito de propriedade; XXIII - a propriedade atenderá à sua função social; Art. 170: A ordem econômica, fundada na valorização do trabalho humano e na livre iniciativa, tem por fim assegurar a todos existência digna, conforme os ditames da justiça social, observados os seguintes princípios: II -propriedade privada; III - função social da propriedade; Art. 182, $\$ 2^{\circ}$ : A propriedade urbana cumpre sua 


\section{Em busca de cidades mais justas por meio da tributação imobiliária}

tratamento constitucional, o artigo 1.228 do Código Civil veio acrescido de um parágrafo que traduz o caráter socialmente funcionalizado da propriedade. ${ }^{5}$ Desse modo, ao direito da propriedade, necessariamente está agregado seu predicado legitimador, que é o princípio da função social. Ou, dito de outro modo, o aspecto estrutural da propriedade - uso, gozo, disposição e direito de reaver o bem por detenção injusta - somente é assegurado pelo sistema brasileiro na medida em que esteja consentâneo com os interesses coletivos contemporâneos ao ambiente em que se situa o bem.

Considerando a referida atmosfera, um princípio próprio do Direito Urbanístico que se intensifica à medida que os problemas urbanos vão-se tornando cada vez mais evidentes é aquele presente no artigo $2^{\circ}$, incisos IX e X, do Estatuto da Cidade. Esse artigo estabelece, como diretriz da política urbana, a "justa distribuição dos benefícios e ônus decorrentes do processo de urbanização", complementado pela "recuperação dos investimentos do Poder Público de que tenha resultado a valorização de imóveis urbanos".

Tais diretrizes da política urbana deveriam ser seguidas principalmente pelas cidades de médio e grande portes. Vale destacar que, segundo a atual dinâmica econômica, aquelas cidades tornaram-se economias de serviços após a perda de peso na geração do PIB pela indústria (Santos, 2012). O resultado disso é a intensificação da polarização espacial, tornando-as polos que seguem atraindo capital e população. Nessas condições, a terra urbana passou a ser mais disputada e valorizada, tornando-se uma fronteira para a aplicação de grande rentabilidade pelo capital imobiliário. E a produção de moradias deixou de ser considerada uma necessidade vital, passando a ser tratada como patrimônio a ser valorizado (Rolnik, 2015).

Quando a valorização das propriedades imobiliárias decorre de intervenção e investimentos públicos, é preciso avaliar quem ganha e quem perde para, então, se imporem mecanismos de compensação de benefícios e ônus criados. A partir da lógica distributiva, que emana das referidas diretrizes urbanísticas, busca-se levar ao alcance da coletividade em geral, e não apenas de proprietários isolados, os efeitos do desenvolvimento urbano, bem como desestimular ações contrárias a um eficiente aproveitamento de espaços bem aprovisionados de infraestrutura e serviços públicos. É nesse contexto que a tributação sobre a propriedade imobiliária deve ser utilizada, não apenas como instrumento de arrecadação fiscal, mas também para estimular o uso da terra urbana em conformidade com os princípios do Direito Urbanístico.

função social quando atende às exigências fundamentais de ordenação da cidade expressas no plano diretor. Art. 186: A função social é cumprida quando a propriedade rural atende, simultaneamente, segundo critérios e graus de exigência estabelecidos em lei, aos seguintes requisitos: I - aproveitamento racional e adequado; II - utilização adequada dos recursos naturais disponíveis e preservação do meio ambiente; III - observância das disposições que regulam as relações de trabalho; IV - exploração que favoreça o bem-estar dos proprietários e dos trabalhadores.

$5 \$ 1^{\circ}-O$ direito de propriedade deve ser exercido em consonância com as suas finalidades econômicas e sociais e de modo que sejam preservados, de conformidade com o estabelecido em lei especial, a flora, a fauna, as belezas naturais, o equilíbrio ecológico e o patrimônio histórico e artístico, bem como evitada a poluição do ar e das águas. 


\subsection{Tributação imobiliária na América Latina e Brasil: uma sintese $e^{6}$}

A implantação do imposto sobre a propriedade imobiliária foi efetivada na maioria dos países da América Latina. Entretanto, é possível observar, a partir de uma análise sistemática e comparativa entre os países, uma grande diversidade na forma de gestão e instituição do imposto. Outro ponto identificado é a desestrutura na divulgação de informações sobre seu desempenho. Por vezes, o próprio poder público desconhece as principais características dos sistemas implantados e seus mecanismos de reforma.

Estas são as principais conclusões de um estudo elaborado pelo Lincoln Institute of Land Policy entre os anos de 2000 e 2008 (Cesare, 2010), comparando-se a administração do imposto territorial em 13 países da América Latina, perfazendo-se um total de 66 jurisdições avaliadas. A análise a seguir foi fundamentada a partir dos dados coletados na realidade tributária de 12 países da América Latina: Argentina, Brasil, Chile, Colômbia, Costa Rica, Guatemala, Honduras, México, Panamá, Paraguai, Peru e República Dominicana. Observe-se o desempenho geral desse imposto nos países citados, analisando-o como fonte de recurso, sua relação com o PIB per capita, sua relação com o tamanho da população, sua representação em porcentagem do PIB e, por fim, as características essenciais do imposto em cada localidade.

A carga tributária total na América Latina encontra-se em torno de 19\% do PIB. O imposto sobre propriedade imobiliária representa, em média, 1,6\% dessa carga tributária, sendo que os ganhos máximos obtidos nessa região giram em torno de $0,60 \%$ do PIB. Em geral, nos países mais desenvolvidos, a arrecadação desse imposto representa pelo menos 1\% do PIB, atingindo limites de 3\% a 4\% no Canadá, Estados Unidos e Reino Unido. Em contraste, na América Latina, em vários países, os ganhos com o imposto de propriedade são mais baixos que $0,50 \%$ do PIB.

Como tendência geral, verificou-se que, à medida que o PIB per capita medido por Paridade de Poder Aquisitivo (PPA) aumenta, a arrecadação com o imposto predial também cresce, excetuando-se apenas México, República Dominicana e Costa Rica, países nos quais o PIB medido por PPA fica acima da média e a arrecadação por imposto territorial está abaixo da média dos outros países.

Quanto aos impostos cobrados pelos estados, ${ }^{7}$ observa-se que representam, em média, 0,29\% do PIB, mas com grande diferença entre essas esferas de governo. As receitas advindas do imposto de propriedade recolhido pelos municípios como percentagem do PIB são mais elevadas do que a média registrada para os estados. Considerando cinquenta casos observados, os municípios recolhem, em média, 0,72\% de seu PIB em imposto predial. A arrecadação mais alta em 2004 foi a do município de

\footnotetext{
${ }^{6}$ Esta parte do artigo se baseia na síntese elaborada por Natália Sales e Carmem Matos para o grupo de pesquisa sobre Tributação Imobiliária, sob minha coordenação.

7 Governos regionais são aqueles que administram territórios menores do que estados nacionais, porém maiores do que os governos locais, podendo ser chamados de governos estaduais, provinciais ou departamentais.
} 


\section{Em busca de cidades mais justas por meio da tributação imobiliária}

São Paulo (1,49\% do PIB). Existe uma variação considerável entre os municípios estudados e não se detectou tendência clara em relação ao comportamento fiscal no período em análise.

Após a análise da performance em geral, destacam-se as características desse imposto e os pontos de divergência em cada localidade. Inicialmente, salienta-se que o imposto costuma ser de responsabilidade local. No entanto, dependendo do critério de competência adotado, pode ficar a cargo do estado. Há uma grande diversidade na fixação da responsabilidade tributária nos países da América Latina. Algumas vezes, ocorre descentralização de sua instituição e cobrança, como, por exemplo, nos casos de Brasil e Venezuela. Outras vezes, o imposto é centralizado na esfera federal e distribuído aos demais entes, como no caso do Chile.

Em segundo lugar, nota-se que a inclusão do possuidor de imóvel como contribuinte é fundamental para expandir a natureza universal do imposto, em função do grande número de assentamentos informais na América Latina. À exceção de Equador e de Baruta (município da Venezuela), outros países como Argentina, Bolívia, Brasil, Chile, Colômbia, Costa Rica, Guatemala, Honduras, México, Peru, Uruguai e Venezuela incluem a propriedade e a posse como fato gerador da incidência do imposto sobre a propriedade. No Peru, considera-se que o possuidor e o detentor são titulares da obrigação tributária. Na Argentina e na Guatemala, os detentores de bens do Estado são contribuintes para fins de obrigações fiscais. No caso do México, o imposto é aplicado aos bens públicos quando utilizados por entidades privadas.

Quanto à base de cálculo, que se apresenta como um dos poucos pontos de convergência entre as jurisdições, é fixada pelo valor de mercado do solo e da construção. Em relação às alíquotas, um dos critérios mais empregados para a fixação de taxas é a classificação de acordo com o uso do imóvel (terreno baldio, imóvel comercial ou residencial). De acordo com as situações identificadas, o número de classes estabelecidas para a aplicação de taxas varia entre 1 e 19. A estrutura dos critérios é complexa e, usualmente, apresenta definiçóes subjetivas, induzindo o contribuinte a omitir informaçóes. Entretanto, muitas jurisdiçóes optam pela taxa única.

Os dados apontam uma tendência em se tributarem mais os imóveis vazios, já que a média das taxas aplicadas aos terrenos baldios excede em 165\% e 75\%, respectivamente, às médias das propriedades residenciais e não residenciais. Esse resultado sugere a existência de um nítido incentivo ao desenvolvimento urbano por meio do combate à especulação imobiliária com a instituição de sobretaxas, cuja aplicação é relativamente comum nas jurisdições analisadas, podendo representar aumento de $100 \%$ da taxa inicial. Em geral, essas sobretaxas são fixadas para sancionar os imóveis subutilizados, não utilizados ou com a construção paralisada, ou ainda aqueles que não cumprem as normas pertinentes.

Uma característica importante para a configuração da performance desse imposto é a concessão de benefícios tributários. Em todos os casos estudados, os imóveis do Estado estão livres de impostos. Somente no México e no Peru, esses benefícios estão vinculados a prédios que exerçam atividades essenciais. As escolas, igrejas e embaixadas também são contempladas. Embora seja possível conceder isenção para famílias de baixa renda e propriedade de baixo valor, essa questão não é tratada com a relevância necessária. À revelia disso, entre 2000 e 2006 houve concessão de anistia ou descontos entre $15 \%$ e $27 \%$ a 96 casos estudados, sendo identificados benefícios fiscais em cerca de $30 \%$ deles, incluindo descontos para pagamento antecipado. 
O cadastramento, embora ocupe posição de destaque na gestão pública, não é elaborado ou atualizado satisfatoriamente. $\mathrm{Na}$ maioria dos casos, não se realizam inspeçôes periódicas nos imóveis registrados, ocorrendo apenas pontualmente, a fim de atender à demanda de planos. Em alguns países, as inspeções acontecem a cada cinco anos. A maioria não apresenta frequência fixa para inspeção. Apesar de ser essencial para as atividades municipais, não é raro encontrar cadastros que não podem executar as atividades fiscais, nem mesmo as básicas.

Cabe destacar que os valores defasados afetam diretamente a eficiência do imposto como promissora fonte de recursos, provocando erros e distorções que afetam a justa distribuição da carga tributária e a confiança no sistema. O nível médio para avaliação e cálculo do imposto gira em torno de $60 \%$ do valor de mercado dos imóveis. Em média, a arrecadação atinge somente $67 \%$ dos impostos instituídos. Cabe ressaltar ainda que a falta de resposta a muitas perguntas das pesquisas realizadas sugere que o problema é maior do que os resultados obtidos.

Por fim, evasão fiscal é uma questão preocupante e muito presente na realidade da América Latina. A administração pública atribui à cultura de "não pagar” o resultado da pouca arrecadação, mas o estudo do Lincoln Institute sugere que é mais correto considerar que essa prática esteja atrelada à cultura do "não cobrar". Essa avaliação corresponde bem ao caso brasileiro, como se observa na seção a seguir.

\section{0 cenário brasileiro: municípios fluminenses e arrecadação tributária}

Esta pesquisa utilizou os dados secundários disponíveis no sítio eletrônico da Secretaria do Tesouro Nacional. ${ }^{8}$ Trata-se de valores que constam nos orçamentos municipais e que permitem a elaboração de um cenário brasileiro e sudestino para a análise do caso dos municípios fluminenses. O foco do estudo é o IPTU, mas também foram levantadas informações sobre a arrecadação de outro tributo imobiliário, o ITBI, apurado a cada transação que envolve a transmissão de bens imobiliários intervivos.

O estudo partiu da premissa de que existem melhores condiçôes técnicas e econômicas para arrecadar tributos em geral onde a atividade econômica é maior. E essa maior atividade econômica está concentrada nas cidades maiores, aquelas que necessitam contar com instrumentos de ordenação urbanística, pois sentem maior pressão demográfica, em virtude das oportunidades de emprego que oferecem (Santos, 2012 e 2014a). Tais condições estão presentes nos estados das regiões Sudeste e Sul, sendo que o estado de São Paulo segue como a "locomotiva do país", como foi chamado na década de 1970. Ainda que, desde então, seu peso no PIB brasileiro tenha declinado de mais da metade para menos de uma terça parte, trata-se da principal força produtiva do Brasil $(32,1 \%)$, com praticamente três vezes mais importância que o estado do Rio de Janeiro (11,8\%), a segunda maior economia estadual. ${ }^{9}$

\footnotetext{
${ }^{8}$ No link Finbra (Finanças do Brasil - Dados Contábeis dos Municípios). Disponível em http://www.tesouro. fazenda.gov.br/pt_PT/contas-anuais.

9 IBGE - Contas Regionais do Brasil, 2013.
} 
A pesquisa focou-se nos municípios com população superior a duzentos mil habitantes e no campo, e a investigação foi centrada nos municípios fluminenses. O critério do tamanho da população foi estabelecido pelo Censo Demográfico de 2010, o que inclui municípios que, em 2000, ainda não haviam atingido duzentos mil habitantes.

\subsection{Os municípios fluminenses no cenário brasileiro}

A segunda maior economia estadual brasileira conta com 13 municípios que têm população superior a duzentos mil habitantes, sendo o maior deles sua capital, que foi capital do país de 1763 até 1960, quando, então, inaugurou-se Brasília.

$\mathrm{Na}$ Tabela 1, apresenta-se um pequeno perfil desses municípios, sendo que apenas três deles não estão situados na Região Metropolitana do Rio de Janeiro (Campos dos Goytacazes, Macaé e Volta Redonda). Vale dizer que os outros dez fazem parte de uma mesma aglomeração urbana nucleada pela capital estadual.

Tabela 1. Perfil dos municípios fluminenses

\begin{tabular}{|l|c|c|c|c|}
\hline Municípios & $\begin{array}{c}\text { PIB per capita } \\
\mathbf{2 0 1 2}(\mathbf{R} \mathbf{\$})\end{array}$ & $\begin{array}{c}\text { Incidência de po- } \\
\text { breza (\%) 2003 }\end{array}$ & $\begin{array}{c}\text { Arrecadação de } \\
\text { IPTU (mil reais) } \\
\mathbf{2 0 1 4}\end{array}$ & $\begin{array}{c}\text { Arrecadaçáo de } \\
\text { ITBI (mil reais) } \\
\mathbf{2 0 1 4}\end{array}$ \\
\hline Rio de Janeiro & 34.572 & 23,85 & 2.002 .165 & 741.677 \\
\hline São Gonçalo & 11.787 & 39,86 & 51.920 & 18.179 \\
\hline Duque de Caxias & 31.280 & 53,53 & $53.551\left(^{*}\right)$ & $12.219\left(^{*}\right)$ \\
\hline Nova Iguaçu & 13.303 & 54,15 & 39.993 & 15.747 \\
\hline Niterói & 30.729 & 12,47 & 232.784 & 87.061 \\
\hline Belford Roxo & 15.893 & 60,06 & $9.763\left(^{*}\right)$ & $2.341\left(^{*}\right)$ \\
\hline Campos dos Goytacazes & 95.552 & 33,26 & 31.340 & 20.759 \\
\hline São João de Meriti & 12.406 & 47,00 & $\mathrm{ND}$ & $\mathrm{ND}$ \\
\hline Petrópolis & 30.732 & 15,97 & 50.533 & 15.985 \\
\hline Volta Redonda & 35.310 & 10,90 & 51.156 & 5.115 \\
\hline Magé & 10.899 & 64,02 & $\mathrm{ND}$ & $\mathrm{ND}$ \\
\hline Itaboraí & 13.912 & 59,43 & 16.175 & 10.090 \\
\hline Macaé & 66.344 & 14,65 & $27.218\left(^{*}\right)$ & $20.720\left(^{*}\right)$ \\
\hline
\end{tabular}

Fonte: Cidades/IBGE. Acesso em 6/10/2015.

(*) Dados referentes ao ano de 2013.

ND - Dados não disponíveis nos anos 2014 e 2013 
Como os dados indicam, os municípios de Campos dos Goytacazes e Macaé possuem um PIB per capita muito acima dos demais municípios, o que se deve ao peso do petróleo na economia local. O caso de Campos dos Goytacazes se destaca porque sua população pouco cresceu, mesmo depois de as receitas petrolíferas (royalties e participações especiais) terem tornado o município campeão de recebimento dessa fonte orçamentária (Santos, 2016). Ainda assim, a taxa de incidência de pobreza desse município foi superior ao dobro da apresentada por Macaé.

Os municípios já consolidados ${ }^{10}$ de Niterói, Petrópolis e Volta Redonda, além da capital, apresentam valores semelhantes de PIB per capita e também apresentaram incidência de população de baixa renda semelhante. Os demais apresentaram um produto que equivale a pouco mais de uma terça parte dos primeiros. A exceção é Duque de Caxias, cujo PIB per capita, próximo do produto da capital, está assentado na economia do petróleo, por causa da Refinaria Duque de Caxias. Apesar disso, o percentual de pobres em sua população o aproxima dos outros municípios de baixo PIB per capita.

Ao se lançar o olhar para a arrecadação dos tributos incidentes sobre a propriedade imobiliária, contudo, verifica-se que Rio de Janeiro e Niterói se destacam dos demais. Somente nesses dois municípios, a atual capital e a capital do antigo estado do Rio de Janeiro, ${ }^{11}$ a arrecadação desses tributos se mostrou expressiva. Nos demais, foi baixo o valor arrecadado com IPTU e ITBI, sendo que dois desses municípios (Magé e São João de Meriti) nem informaram os valores arrecadados. Esses resultados, portanto, sugerem a existência de três grupos de municípios com capacidades distintas de arrecadar os tributos considerados: i) o primeiro é constituído das "duas capitais", com melhor desempenho; ii) o segundo é o grupo dos municípios consolidados, ou seja, cuja população é elevada mas estável, não sofrendo influência da economia do petróleo; e iii) os municípios positivamente afetados pelo petróleo. Acreditamos que os municípios integrantes do primeiro e do terceiro grupos têm condições de melhorar a arrecadação sobre a propriedade imobiliária, mas não os do segundo grupo, cuja elevada incidência de pobreza impõe limites mais estreitos, para que sua população suporte o aumento da carga tributária.

$\mathrm{Na}$ Tabela 2, apresenta-se a distribuição dos municípios brasileiros com mais de duzentos mil habitantes segundo regióes (Censo de 2010), além do peso do conjunto de todos os municípios na arrecadação total do país em relação aos dois principais tributos incidentes sobre a propriedade imobiliária, o IPTU e o ITBI, em 2013, último ano para o qual havia informações disponíveis.

\footnotetext{
${ }^{10}$ Foram considerados "municípios consolidados" aqueles cuja população já se estabilizou.

${ }^{11}$ Niterói foi capital do estado do Rio de Janeiro até 1975, quando foi instituída a fusão entre os estados da Guanabara (antigo Distrito Federal) e o Rio de Janeiro. A partir de então, a cidade do Rio de Janeiro deixaria de ser a cidade-estado da Guanabara e passaria a ser a capital do novo estado do Rio de Janeiro.
} 
Em busca de cidades mais justas por meio da tributação imobiliária

Tabela 2. Participação percentual dos municípios com mais de 200 mil habitantes na arrecadação do IPTU e do ITBI dos municípios brasileiros

\begin{tabular}{|l|c|c|c|c|}
\hline Regióes/Estados & $\begin{array}{c}\text { Número total de } \\
\text { municípios }\end{array}$ & $\begin{array}{c}\text { Número de muni- } \\
\text { cípios } \mathbf{2 0 0} \text { mil } \\
\text { habitantes }\end{array}$ & $\begin{array}{c}\text { IPTU 2013 (> 200 } \\
\text { mil hab.) \% sobre } \\
\text { o total }\end{array}$ & $\begin{array}{c}\text { ITBI 2013 (> 200 } \\
\text { mil hab.) \% sobre } \\
\text { o total }\end{array}$ \\
\hline Norte & 450 & 10 & 1,50 & 2,43 \\
\hline Centro-Oeste & 467 & 7 & 4,84 & 7,20 \\
\hline Nordeste & 1.794 & 26 & 7,25 & 12,12 \\
\hline Sudeste & 1.668 & 69 & 73,24 & 58,82 \\
\hline MG & 853 & 13 & 7,24 & 10,07 \\
\hline RJ & 92 & 13 & 12.15 & 12,51 \\
\hline SP & 645 & 39 & 53,00 & 34,55 \\
\hline Sul & 1.191 & 21 & 13,16 & 19,43 \\
\hline Brasil & 5.570 & 133 & 100,00 & 100,00 \\
\hline
\end{tabular}

Fonte: Elaboração própria, com base nos dados STN/Finbra. Finanças do Brasil - Dados Contábeis dos Municípios, 2013.

O maior número de municípios com população superior a duzentos mil habitantes encontra-se na Região Sudeste, onde a rede municipal é grande, porém menor do que a da Região Nordeste, que, com seus 1.794 municípios, têm apenas 26 com mais de duzentos mil habitantes. A distribuição mais capilarizada desses grandes municípios pode ser considerada um indicador de maior dinamismo regional do Sudeste em comparação ao Nordeste.

O IPTU e o ITBI são os principais tributos incidentes sobre a propriedade imobiliária. ${ }^{12}$ Conforme já mencionado, o ITBI só incide no ato da transferência da propriedade intervivos e, portanto, de modo pontual. É diferente o caso do IPTU, um tributo anualmente pago pela propriedade de imóveis prediais ou territoriais urbanos. Nesse caso, importa sobremaneira a forma como o tributo é administrado e em que âmbito se destaca o valor do patrimônio imobiliário, considerado na Planta Genérica de Valores. Não causa surpresa, assim, que, nos locais em que há maior peso no PIB brasileiro, também o patrimônio imobiliário seja mais elevado, como ocorre na Região Sudeste. Nos estados do Sudeste, foram arrecadados três em cada quatro reais do tributo $(73,24 \%$ do total), sendo os municípios paulistas responsáveis por mais da metade de toda a arrecadação do país (53\%). Os municípios fluminenses vêm em segundo lugar, porém com muito menos peso, equivalente a $12,15 \%$, quase o mesmo percentual de sua participação no total de ITBI arrecadado no Brasil.

\footnotetext{
${ }^{12}$ Além do IPTU e do ITBI, incidem sobre a propriedade imobiliária as contribuições de melhoria e o Imposto Territorial Rural (de competência federal), ambos com participação muito pequena na arrecadação fiscal, conforme apontado por Santos (2014b).
} 
É muito instigante verificar que o peso do Sudeste no ITBI $(58,82 \%)$ é maior que nas demais regiōes, embora bem menos concentrado do que ocorre com o IPTU $(73,24 \%)$, devido à menor participação dos municípios paulistas (34,55\% em relação aos 53\% do IPTU). Em todas as demais regiōes - inclusive entre os demais estados do Sudeste -, o peso percentual de arrecadação do ITBI foi superior ao percentual do apurado do IPTU nos municípios com mais de duzentos mil habitantes. Esse resultado deve estar associado à dificuldade que os municípios enfrentam de melhorar a arrecadação do IPTU, enquanto o ITBI, por ser pago apenas no momento da transação imobiliária, deixa os governos municipais com melhores condiçôes políticas de impor uma base de cálculo mais elevada. ${ }^{13}$

O maior peso dos municípios paulistas - e a equivalência entre os fluminenses - na arrecadação do IPTU em comparação ao ITBI sugere que há melhor administração desse tributo - o principal sobre a propriedade imobiliária nos municípios que se situam nas principais economias estaduais. ${ }^{14}$ Também é em São Paulo que se concentra o maior número de municípios de grande porte, ou seja, aqueles com mais de duzentos mil habitantes (como considerado neste estudo). São justamente os municípios populosos que mais precisam de instrumentos de política urbana com vistas a ordenar o respectivo crescimento.

Na tabela a seguir, apresenta-se a evolução da participação percentual do IPTU e do ITBI no PIB dos anos 2000, 2005, 2010 e 2013.

Tabela 3. Evolução da participação percentual do IPTU e ITBI no PIB dos anos 2000, 2005, 2010 e $2013(\%)$

\begin{tabular}{|l|c|c|c|c|c|c|c|c|}
\hline Municípios & \multicolumn{4}{|c|}{ IPTU } & \multicolumn{4}{c|}{ ITBI } \\
\hline & 2000 & 2005 & 2010 & 2013 & 2000 & 2005 & 2010 & 2013 \\
\hline Brasil & 0,45 & 0,46 & 0,42 & 0,43 & 0,09 & 0,09 & 0,14 & 0,17 \\
\hline Sudeste & 0,35 & 0,34 & 0,30 & 0,31 & 0,06 & 0,06 & 0,08 & 0,10 \\
\hline $\begin{array}{l}\text { Estado do Rio de } \\
\text { Janeiro }\end{array}$ & 0,08 & 0,07 & 0,05 & 0,05 & 0,02 & 0,01 & 0,02 & 0,02 \\
\hline $\begin{array}{l}\text { Municípios brasileiros } \\
\text { com } 200 \text { mil } \\
\text { habitantes }\end{array}$ & 0,33 & 0,34 & 0,32 & 0,33 & 0,06 & 0,06 & 0,10 & 0,12 \\
\hline $\begin{array}{l}\text { Municípios flumi- } \\
\text { nenses com > 200 mil } \\
\text { habitantes }\end{array}$ & 0,06 & 0,06 & 0,05 & 0,05 & 0,01 & 0,01 & 0,02 & 0,02 \\
\hline
\end{tabular}

Fonte: Elaboração própria com base nos dados STN/Finbra. Finanças do Brasil. Dados Contábeis dos Municípios, 2013.

\footnotetext{
13 A transferência da propriedade só ocorre após o registro em cartório, o que estimula os novos proprietários a aceitarem o valor arbitrado pelo Poder Público.

${ }^{14}$ Economias dos estados de São Paulo e Rio de Janeiro.
} 
O desempenho dos dois tributos incidentes sobre a propriedade imobiliária correspondente à proporção do PIB nos anos selecionados sugere a existência de espaço para se melhorar a administração do IPTU, especialmente entre os municípios com população superior a duzentos mil habitantes. Afinal, houve significativo avanço na arrecadação do ITBI, dobrando sua participação percentual ao longo do período, enquanto o peso da arrecadação do IPTU diminuiu.

Como este estudo focaliza os municípios fluminenses com população superior a duzentos mil habitantes, dos quais apenas a capital tem peso significativo em relação ao PIB, a próxima tabela apresenta os valores per capita arrecadados em relação aos dois tributos imobiliários. Objetiva-se comparar o desempenho deles no início e no fim da década, quando houve informação censitária suficiente a permitir o cálculo dos valores arrecadados per capita.

Tabela 4. Arrecadação per capita do IPTU e ITBI nos municípios fluminenses com população superior a duzentos mil habitantes

\begin{tabular}{|l|c|c|c|c|}
\hline Município & IPTU 2000 & IPTU 2010 & ITBI 2000 & ITBI 2010 \\
\hline Rio de Janeiro & 106,22 & 226,54 & 22,32 & 78,63 \\
\hline São Gonçalo & 25,61 & 35,81 & 2,41 & 8,20 \\
\hline Duque de Caxias & 21,03 & 56,92 & 1,83 & 4,77 \\
\hline Nova Iguaçu & 13,17 & 35,76 & 1,39 & 7,91 \\
\hline Niterói & 129,84 & 371,46 & 27,18 & 114,96 \\
\hline Belford Roxo & 8,24 & 13,46 & 0,37 & 3,72 \\
\hline Campos dos Goytacazes & 11,24 & 39,11 & 3,11 & 16,17 \\
\hline São João de Meriti & 14,30 & 30,88 & 0,56 & 1,24 \\
\hline Petrópolis & 72,69 & 141,83 & 7,21 & 32,14 \\
\hline Volta Redonda & 79,29 & 150,36 & 3,71 & 15,24 \\
\hline Magé & 7,84 & 24,49 & 1,12 & 2,82 \\
\hline Itaboraí & 10,31 & 48,49 & 2,68 & 23,18 \\
\hline Macaé & 14,11 & 53,31 & 7,63 & 48,24 \\
\hline $\begin{array}{l}\text { Média dos munićpios } \\
\text { fluminenses }\end{array}$ & 63,37 & 132,86 & 13,38 & 43,34 \\
\hline $\begin{array}{l}\text { Média dos municípios } \\
\text { brasileiros }\end{array}$ & 33,53 & 86,34 & 7,05 & 29,39 \\
\hline
\end{tabular}

Fonte: Elaboração própria com dados dos censos demográficos 2000 e 2010 e STN/Finbra - Finanças do Brasil. Dados Contábeis dos Municípios, 2013.

A arrecadação per capita dos dois tributos imobiliários acompanha a divisão dos municípios fluminenses naqueles três grupos antes mencionados, destacando-se, mais uma vez, as "duas capitais". Chama a atenção, contudo, o fato de os municípios fluminenses apresentarem, em média, pior de- 
sempenho que o do conjunto dos municípios brasileiros com mais de duzentos mil habitantes ao longo da década 2000-2010. Em 2000, por exemplo, os municípios de Niterói e do Rio de Janeiro foram os que apresentaram valores per capita superiores a cem reais, bem acima da média dos demais municípios. Desses, apenas Petrópolis e Volta Redonda se destacaram, resultado que deve estar relacionado à presença de uma população que, se não cresce a taxas superiores à média estadual, pelo menos sustenta um índice já consolidado nos centros urbanos microrregionais. Os outros são municípios cuja dinâmica depende da capital estadual, uma vez que se situam na região metropolitana. Isso porque, apesar de que alguns virem experimentando o fortalecimento dentro da rede urbana metropolitana, ${ }^{15}$ sua população conta com expressivo contingente de pessoas com baixo rendimento, o que limita a capacidade de os governos imporem uma carga tributária própria de maior peso.

Os valores apurados em 2010 sugerem que a situação vigente em 2000 mudou pouco, exceto pelos destaques positivos de Niterói e Itaboraí, ao lado do crescimento acima da média dos municípios de Campos dos Goytacazes e Macaé. No caso de Itaboraí, o resultado deve estar associado ao impacto positivo na economia municipal, devido às obras do Complexo Petroquímico do Rio de Janeiro (Comperj). Em relação a Campos dos Goytacazes e Macaé, o resultado deve estar relacionado à necessidade de se diversificarem as fontes de arrecadação municipal, diante da mudança iminente na legislação das receitas petrolíferas. ${ }^{16}$ Cabe ainda destacar que o aumento generalizado da arrecadação per capita do IPTU não acompanhou o aumento do PIB na primeira década do século, como exposto na Tabela 3. A evolução do ITBI no período ocorreu num ritmo mais intenso que o do IPTU, ainda que a distribuição desse avanço entre os municípios fluminenses tenha acompanhado o desempenho desse último imposto.

A análise das informações sugere espaço suficiente para se melhorar a administração do principal tributo incidente sobre a propriedade imobiliária, o IPTU. Isso fica claro quando se compara com o melhor desempenho do ITBI. Como já mencionado, tal resultado deve ser atribuído ao maior poder de enforcement dos governos municipais em imputar um valor superior para fins de arrecadação do ITBI em relação aos valores venais referentes ao IPTU.

Um estudo realizado por Carvalho Jr. (2011) sobre a administração do IPTU no município do Rio de Janeiro concluiu que sua baixa participação na arrecadação fiscal não se devia às alíquotas do tributo, mas a uma gestão inadequada. A desatualização da Planta Genérica de Valores (PGV) em relação aos preços de mercado dos imóveis era maior entre os imóveis mais antigos do que em relação aos novos. No entanto, mesmo nos novos, prevalece uma grande diferença entre os preços praticados no mercado imobiliário e no cadastro da prefeitura. E, sem dúvida, a análise dos resultados apresentados nas "duas capitais" sugere que a capital fluminense é o município que conta com melhor suporte técnico na gestão municipal, bem acima da média dos municípios fluminenses. Ainda assim, os demais municípios do estado do Rio de Janeiro precisam avançar muito para se aproximar do desempenho dos municípios paulistas, aqueles de melhor resultado arrecada-

\footnotetext{
${ }^{15}$ Caso do município de Nova Iguaçu.

${ }^{16}$ Em 2012, entrou em vigor a Lei n. 12.734, que alterou a partilha das receitas petrolíferas entre os entes federativos, anteriormente muito concentrada nos estados e municípios considerados "produtores", casos de Campos dos Goytacazes e Macaé.
} 
tório do IPTU. Nesse sentido, destaca-se que a capital paulista já tornou obrigatória a atualização a cada quatro anos de sua PGV, o que já deveria ter sido realizado na cidade do Rio de Janeiro, onde um grande conjunto de obras públicas preparatórias para os Jogos Olímpicos de 2016 dinamizou o mercado imobiliário. Sem melhorar a administração dos tributos imobiliários, a prefeitura deixa de captar parte dessa valorização da terra urbana.

A importância na melhora da administração do IPTU não é apenas uma necessidade para aumentar a arrecadação fiscal, ainda mais no contexto de crise fiscal que o país atravessa. Sua relevância também é acentuada porque se trata de um tributo com função extrafiscal incluída na política urbana brasileira, além de ser uma parte importante da política tributária comprometida com a justiça fiscal e social.

\subsection{Pesquisa de campo realizada nos municípios fluminenses ${ }^{17}$}

A pesquisa de campo sobre a administração do IPTU abrangeria oito dos 13 municípios fluminenses com mais de duzentos mil habitantes: Niterói, Rio de Janeiro, Petrópolis, Volta Redonda, São Gonçalo, Duque de Caxias, Campos dos Goytacazes e Macaé. Entretanto, após diversas tentativas de contato, inclusive realizando-se reuniōes com membros das secretarias de fazenda, foi possível obter dados apenas em São Gonçalo, Duque de Caxias e Macaé. Em conversa com o subsecretário de Administração e Gestão Fazendária do município de Niterói, foi-nos sugerido, inclusive, que a pesquisa fosse conduzida no sentido de priorizar análises sobre a gestão do ITBI, que, segundo afirmado por ele, seria um tributo mais fácil de manejar do que o IPTU.

Uma abordagem normativa a respeito da adequada administração do tributo aponta para a necessidade de: a) atualizar a lei de perímetro urbano; b) que o cadastro imobiliário abranja todos os domicílios; e c) que a planta genérica de valores esteja atualizada conforme a valorização do mercado imobiliário. Não foi esse o quadro apurado nos três municípios que aceitaram responder a essa investigação.

Tabela 5. Grau de cobertura do cadastro imobiliário nos municípios selecionados

\begin{tabular}{|l|l|l|l|}
\hline Municípios/Unidades & São Gonçalo & Macaé & $\begin{array}{l}\text { Duque de } \\
\text { Caxias }\end{array}$ \\
\hline Total de unidades cadastradas & 466.080 & 81.475 & 354.910 \\
\hline Unidades residenciais cadastradas & 289.261 & 33.074 & 205.406 \\
\hline Unidades não residenciais cadastradas & 101.083 & 23.727 & 31.652 \\
\hline Unidades territoriais cadastradas & 75.736 & 24.679 & 117.852 \\
\hline
\end{tabular}

\footnotetext{
${ }^{17}$ Este trecho se baseia na síntese elaborada por Pedro Vasques para o Grupo de Pesquisa sobre Tributação Imobiliária, sob minha coordenação.
} 


\begin{tabular}{|l|l|l|l|}
\hline Municípios/Unidades & São Gonçalo & Macaé & $\begin{array}{l}\text { Duque de } \\
\text { Caxias }\end{array}$ \\
\hline Unidades residenciais/unidades cadastradas (\%) & 62,1 & 40,6 & 57,9 \\
\hline Unidades não residenciais/unidades cadastradas (\%) & 21,7 & 29,1 & 8,9 \\
\hline Unidades territoriais/unidades cadastradas (\%) & 16,2 & 30,3 & 33,2 \\
\hline
\end{tabular}

Fontes: IBGE - Censo Demográfico 2010 e Pesquisa de Campo 2015.

Conforme se verifica na tabela acima, em nenhum dos três municípios há cobertura da totalidade das unidades cadastradas, sendo que o de Macaé não atinge nem a metade, o que sugere o elevado grau de desconhecimento desse município em relação ao próprio território. Nessas condições, não é possível cumprir adequadamente com sua responsabilidade pela política urbana, nem mesmo com a arrecadação potencial de sua tributação própria. Macaé também apresentou o menor grau de dependência de seu cadastro imobiliário em relação às unidades residenciais (41\%), percentual pouco maior que aquele relativo às unidades não residenciais $(29,1 \%)$ e territoriais $(30,3 \%)$.

São Gonçalo apresentou dados mais próximos do que se espera de um município preocupado em melhorar a gestão de seu território: maior percentual de cobertura cadastral de suas unidades residenciais, que, por sua vez, representam um percentual superior aos $60 \%$ do total das unidades cadastrais.

Tabela 6. Participação percentual entre o montante lançado e o arrecadado do IPTU nos municípios selecionados

\begin{tabular}{|l|l|l|l|}
\hline & São Gonçalo & Macaé & Duque de Caxias \\
\hline Unidades residenciais & 46,95 & 40,65 & 46,78 \\
\hline Unidades não residenciais & 28,34 & 57,12 & 60,71 \\
\hline Unidades territoriais & 10,13 & 42,58 & 18,22 \\
\hline Total & 36,43 & 45,87 & 46,92 \\
\hline
\end{tabular}

Fonte: Pesquisa de campo, 2015.

A partir dos dados coletados, verificou-se que, ao menos no ano de 2013, a arrecadação relativa ao montante lançado variou entre $36,43 \%$ e $46,92 \%$, revelando-se baixa no que diz respeito a seu potencial, especialmente no que se refere ao caso de Macaé, que, conforme já mencionado, apresenta índice de pobreza inferior ao dos outros dois municípios aqui considerados.

É importante notar que, tanto em São Gonçalo como em Duque de Caxias, os menores percentuais entre o que foi cobrado e o que foi arrecadado fazem referência às unidades territoriais. Em outras palavras, o primeiro arrecadou apenas $10 \%$ do que efetivamente foi lançado para mencionada categoria. Já no caso do segundo município, embora ainda apresente valor percentual reduzido, esse 


\section{Em busca de cidades mais justas por meio da tributação imobiliária}

montante sobe para 18\%. Levando-se em conta que esses municípios são densamente ocupados, os dados identificados reforçam o baixo interesse das administrações municipais em conduzir esforços para cobrar o imposto nas áreas não edificadas, o que representa uma reduzida parcela de seus territórios. Também em conformidade com as expectativas, os municípios de maior peso econômico, Duque de Caxias e Macaé, arrecadaram, respectivamente, 57\% e 61\% do montante efetivamente cobrado para as unidades não residenciais, ou seja, os imóveis comerciais. Mas, de modo geral, a relação percentual verificada nos municípios entrevistados apontou para uma distância substantiva entre o que foi lançado e o que foi efetivamente arrecadado nesse ano, o que nos permite questionar se os mecanismos de gestão e cobrança atualmente empregados por esses municípios são realmente eficientes.

Sobre as medidas referentes à diminuição e à inadimplência do IPTU, levando-se em conta o percentual antes verificado, é possível afirmar que algumas estratégias tradicionais, como, por exemplo, parcelamento, desconto, possibilidade de pagamento na maior parte da rede bancária e nas lotéricas, cobrança judicial - apontadas pelo três municípios como ferramentas utilizadas - aparentam haver atingido o limite máximo na capacidade de ampliação da arrecadação, sendo, portanto, necessário desenvolver outras estratégias para otimizar a gestão desse tributo. Até mesmo o emprego de ferramentas menos tradicionais, como, por exemplo, sistemas georreferenciados de informação, restrições de transferência/venda de propriedades em dívida, inclusão do contribuinte inadimplente em cadastros (da prefeitura, $S P C^{18}$ e Serasa) ${ }^{19}$ protestos da dívida ativa em cartório e realização de leilōes públicos, parece não surtir efeito significativo na melhora da arrecadação. Isso porque, mesmo no caso de São Gonçalo, que aplica todos os mencionados instrumentos, verificou-se a pior relação percentual, com uma arrecadação de apenas 36,43\% do montante total lançado no ano de 2013. Ainda que o referido ano possa não ser representativo, essa análise - em comparação aos dados gerais coletados entre os anos de 2000 e 2013, na seção anterior - confere mais certeza à afirmação de que é necessário desenvolver alternativas que melhorem a gestão do tributo municipal, com vistas a ultrapassar os percentuais existentes.

Outro dado importante acerca dos limites da arrecadação diz respeito às isençôes e imunidades. Ao contrário do que acontece, por exemplo, no município do Rio de Janeiro, em que isençôes e imunidades representam um percentual significativo do valor venal de todas as propriedades inseridas em seu território (65\% para uso residencial e 91\% para territorial, segundo Carvalho Jr [2013]), nos municípios estudados as propriedades imunes e isentas não só representam um percentual baixo de unidades $(0,1 \%$ do total de propriedades em São Gonçalo e 5,37\% do total em Macaé), como também equivalem a um pequeno montante em relação ao valor venal total das propriedades nos respectivos municípios $(0,04 \%$ e $1,72 \%)$.

Sobre a atualização da Planta Genérica de Valores, novamente o município de São Gonçalo se situa atrás dos demais, com a última atualização ocorrida em 2003 (Lei no 41/2003). Em 2011, o município de Macaé atualizou os valores através de alteração na Lei municipal no 133/09. Por fim, Duque de Caxias - que, embora não disponha de registro do último recadastramento de suas proprie-

\footnotetext{
18 Serviço de Proteção ao Crédito.

19 Serasa Experian é uma empresa certificadora de crédito.
} 
dades, segundo informações prestadas por um funcionário da Secretaria de Fazenda - foi o município que atualizou, com mais recenticidade, sua PGV, por meio da Lei no 2.595/13.

\subsection{Municipios fluminenses: um longo caminho a percorrer para avançar na tributação imobiliária}

A análise das informações coletadas por meio de pesquisa de campo e coleta de dados sugere que a melhora na administração do IPTU pode ser verificada com a adoção de medidas já usualmente empregadas por outros municípios, como, por exemplo, condução de recadastramentos periódicos. No caso de São Gonçalo, que apresentou o pior desempenho entre lançamento e arrecadação nas unidades territoriais, não há registro de seu último recadastramento. Como consequência direta desse comportamento por parte da administração municipal, dos três municípios analisados, São Gonçalo foi o que apresentou pior desempenho, arrecadando apenas 36,43\% do total efetivamente lançado. Por outro lado, até mesmo a utilização dos tradicionais instrumentos de cobrança aparenta encontrar um limite em sua eficiência, como se verifica no desempenho dos outros dois municípios estudados.

No que diz respeito à implantação de mecanismos alternativos de cobrança, como, por exemplo, leilão de imóveis ou inclusão em cadastros de inadimplentes, apesar de todos os municípios entrevistados afirmarem a adoção desse recurso, faz-se necessário conduzir novos estudos, a fim de observar de que forma esses instrumentos vêm sendo aplicados. Somente depois de obtidas informaçóes mais detalhadas, será possível analisar os limites de sua eficiência.

Por fim, observa-se que, a despeito das várias discussōes sobre as possíveis aplicaçōes extrafiscais do IPTU, sua gestão é precária, e a arrecadação do tributo encontra limites vários no interior da própria burocracia municipal, dentre os quais destaca-se a dificuldade de se negociar com o Legislativo a atualização dos instrumentos normativos. Quando nem mesmo os elementos básicos da gestão do tributo são observados, sua aplicação em uma perspectiva extrafiscal se apresenta como um horizonte ainda muito remoto.

\section{Conclusões}

Os resultados desta investigação estão alinhados com os apurados por De Cesare (2010), Carvalho Jr. (2011 e 2013) e Luft e Santos (2012): os municípios não exploram com o máximo de eficiência seu potencial arrecadatório sobre a propriedade imobiliária, o que esvazia o conteúdo de instrumento de política urbana do instituto extrafiscal do IPTU. Nessas condições, por que seguir pesquisando o tema da tributação imobiliária no Brasil?

Creio que existem dois motivos principais.

O primeiro deles diz respeito ao longo tempo decorrido entre o lançamento de uma agenda de política urbana e sua disseminação com apreensão pela sociedade, passando a ser cobrado do sistema político. A assembleia da Agência ONU/Habitat II, ocorrida em Istambul, pode ser uma boa referência. A atual Constituição brasileira já estava em vigor desde 1988, com sua inovadora submissão da propriedade 


\section{Em busca de cidades mais justas por meio da tributação imobiliária}

ao cumprimento de uma função social, que ainda se encontrava sujeita à regulamentação do artigo 182, relativo à política urbana, de responsabilidade do município, que foi elevado à condição de ente federativo.

A agenda da política urbana definida pelas Nações Unidas, por meio da Agência Habitat, contribuiu para nortear as políticas urbanas em escala nacional, o que se refletiu na aprovação do Estatuto da Cidade regulando o capítulo da política urbana, mas isso ocorreu apenas em 2001. Muitos dos instrumentos de ordenamento urbanístico regulados nessa lei, contudo, precisam ser novamente regulados, agora em escala municipal. E, quando isso ocorrer, essa regulamentação ainda depende do interesse das prefeituras em conferirem efetividade àqueles instrumentos, como é o caso do IPTU progressivo.

Esse longo período transcorrido entre as inovações normativas e sua efetividade decorre de um processo de reposicionamento - lento - dos atores envolvidos nas políticas públicas. Entre os principais, destacam-se o município, institucionalmente fortalecido na federação, bem como a autonomia conquistada pelo Ministério Público e o protagonismo da Defensoria Pública em relação aos direitos sociais. A crescente expectativa dos direitos de cidadania, por sua vez, resultou na judicialização das políticas públicas, levando o Poder Judiciário a atualizar suas decisões no contexto normativo em que o Estado ampliou seus compromissos com o cidadão. Por isso, não se julga adequado abrir mão de um instrumento jurídico já amplamente regulado em todas as esferas de governo ao argumento de que, até agora, não funcionou. Poderá vir a funcionar caso a sociedade (cidadãos, prefeituras, Ministério Público e Defensoria Pública) cobre sua utilização para mitigar os efeitos da crise urbana, em especial a crise da habitação social.

Uma segunda razão para seguir defendendo o uso da tributação imobiliária (IPTU progressivo) diz respeito ao já referido aumento dos compromissos do Estado (não apenas no Brasil) em relação ao bem-estar social. Este não se reduz aos gastos previdenciários, mas vem-se traduzindo em crescentes despesas com saúde, educação e assistência social. Estas já teriam alcançado os percentuais de gastos com aposentadorias e pensões, cada um deles representando $15 \%$ em relação ao produto, o que perfaz um total de $30 \%$ do PIB, segundo estimativas de Piketty (2013). O direito à moradia, no entanto, vem sendo crescentemente reclamado em face da adoção de políticas habitacionais baseadas na propriedade privada, sendo o Estado desafiado a avançar rumo a políticas de moradia desmercantilizadas (Rolnik, 2015).

Um estudo realizado por Kersternetsky (2012) sobre as transformaçōes do estado de bem-estar social aponta na mesma direção: o bem-estar social tem evoluído para a defesa da reprodução social das famílias, e não apenas da renda do trabalhador. E, entre as necessidades das famílias, a habitação tem importância crucial, pois sua localização pode ampliar ou diminuir, por exemplo, o acesso a serviços de saúde, educação, mobilidade e segurança pública. Aumentar a oferta de moradia, especialmente a de interesse social, é, assim, um objetivo que deve ser perseguido por todos os meios, inclusive pela tributação imobiliária das propriedades que não cumpram sua função social, em conformidade com a política urbana já normatizada no Brasil.

As análises de Piketty e Kersternetsky encontram eco no estudo de Raquel Rolnik (2015) sobre a mudança do significado da moradia no início do século XXI. Transformada em fronteira de aplicação rentável para o capital financeiro, também passou a ser considerada fonte para resguardar a renda familiar de aposentados que adquirem imóveis para locação. No entanto, a mercantilização da habitação vem aprofundando a vulnerabilidade de uma parcela crescente da população em todo o planeta, como bem demonstrado pela autora, o que alimenta a crise urbana. Entre as soluções possíveis para enfrentar esse desafio, encontra-se o aumento da tributação sobre a riqueza e, em particular, sobre a propriedade imobiliária 
urbana. Afinal, não soa razoável que aproximadamente 50\% de como se expressa a riqueza atual se refiram à propriedade de moradias, como identificado por Piketty.

\section{Referências}

BRASIL. Constituição da República Federativa do Brasil de 05 de outubro de 1988.

CARVALHO JR, P. H. O sistema avaliatório municipal de imóveis e a tributação do IPTU no Rio de Janeiro (dissertação). UERJ, 2011.

—. "Situação atual do IPTU no Rio de Janeiro e sua possível reforma", Cadernos do Desenvolvimento Fluminense, n. 1, 2013.

CESARE, Claudia M. de. Reseña del Impuesto Predial en América Latina. S.1.: Lincoln Institute of Land Policy, 2010.

KERSTENETZKY, C. L. O estado do bem-estar social na Idade da Razão: a reinvenção do estado social no mundo contemporâneo. Rio de Janeiro: Elsevier, 2012.

LUFT, Rosângela e SANTOS, Ângela Moulin S. Penalva. “Tributação imobiliária e política urbana no Brasil”. In SANTOS, A. et al. Rio de Janeiro: um território em mutação. Rio de Janeiro: Grama, 2012.

PIKETTY, Thomas. O capital no século XXI. Rio de Janeiro: Intrínseca, 2014.

ROLNIK, R. Guerra dos lugares: a colonização da terra na era das finanças. São Paulo: Boitempo, 2015.

SANTOS, Angela M. S. P. “Cidades médias: novas fronteiras de oportunidades”. In —. Rio de Janeiro: um território em mutação. Rio de Janeiro: Gramma, 2012.

. "Política urbana no contexto federativo brasileiro: entre a cidade do plano e a cidade real". In SANTOS, A. e SANT'ANNA, M. (orgs.). Transformaçôes territoriais no Rio de Janeiro do século XXI. Rio de Janeiro: Gramma, 2014.

—. "Tributação imobiliária: um difícil percurso rumo à política urbana", Finisterra: Revista Portuguesa de Geografia, v. XLIX, n. 97, 2014.

—_. "O município como agente de políticas públicas: o caso dos municípios fluminenses". In SANTOS, A. e GERSCHMAN, S. (orgs.). Saúde e políticas sociais no Rio de Janeiro. Rio de Janeiro: Fiocruz, 2016. 